\title{
Experimental Study on Static and Dynamic Fracture Toughness of Cured Epoxy Resins
}

\author{
Jakub Skoczylas ${ }^{1}$ Sylwester Samborski ${ }^{1}$, Mariusz Kłonica ${ }^{2 *}$ \\ 1 Department of Applied Mechanics, Faculty of Mechanical Engineering, Lublin University of Technology, ul. \\ Nadbystrzycka 36, 20-618 Lublin \\ 2 Department of Production Engineering, Faculty of Mechanical Engineering, Lublin University of Technology, \\ ul. Nadbystrzycka 36, 20-618 Lublin \\ * Corresponding e-mail: m.klonica@pollub.pl
}

\begin{abstract}
The paper investigates experimental results of static and dynamic fracture toughness. The three-point bending test and the Charpy pendulum test were performed for two kinds of polymers: Epidian 5 epoxy resin cured with Z1 curing agent and Epidian 53 epoxy resin cured with Z1 curing agent. The comparison between the values of a maximum static and a maximum dynamic force are discussed as well as the values of static and dynamic fracture toughness, with special emphasis on microscopic views of crack propagation.
\end{abstract}

Keywords: static fracture toughness, dynamic fracture toughness, epoxy resin

\section{INTRODUCTION}

The definition of epoxy resins states that they constitute low-molecular-weight pre-polymers containing more than one epoxide group. Epoxy resins are widely used in many applications such as paints, coatings, adhesives, industrial tooling, aerospace industry, electronic materials and biomedical systems. The materials of that kind possess excellent mechanical properties and are chcaracterized by high adhesiveness to many substrates [4]. The main advantages of polymer matrix composites based on epoxy resins are their high elastic modulus and high tensile strength [16].

Furthermore, due to their wide curing temperature range, low coefficient of thermal expansion, high insulation resistance, and good resistance to chemical corrosion, epoxy resins have been also used e.g. in cryogenic engineering [17]. However, variable thermal conditions of the environment which are found in such industries as aircraft, automotive or medicine, can affect the strength of adhesive joints. As discussed in [5], a thermal shock provoked a $50 \%$ decrease in the shear stress values for the steel specimens bonded with Epidian 5 epoxy adhesive with Z1 curing agent. Thermal fatigue could also cause a decrease of the Young's modulus for epoxy adhesives [6].

Moreover, epoxy resins are rigid and brittle materials which possess low resistance to crack initiation and growth. Hence, their use is limited in some applications, such as structural materials [4]. For brittle materials - where cracks are most involved in the mechanical failure and hardness measurement - it is crucial to predict the fracture toughness which represents the ability of the material to resist crack propagation. It is one of the most essential parameters in fracture mechanics of solid materials $[8,14,15]$. Fracture toughness is determined as a delamination resistance with reference to such materials as carbon fiber reinforced polymeric (CFRP) laminates, the main disadvantage of which is a tendency to delaminate. The finite elements (FE) simulations of the fracture toughness test configurations prior to the physical experiments are helpful and could be an invaluable source of knowledge. The example of such a modeling method is the virtual crack closure technique (VCCT) $[11,12]$. 
The dynamic fracture toughness plays an important role in the engineering applications where brittle materials are used in structural elements and a dynamic event may occur during e.g. crash, explosion, blast, projectile penetration [9]. However, in the case of the dynamic toughness, e.g. determined by the Charpy pendulum test, it is quite difficult to analyze the complicated fracture behavior because the propagation and linkage of microcracks are caused almost simultaneously during the dynamic load [2].

In this paper, the behavior of two cured epoxy resins under static and dynamic loading was analyzed. For brittle materials such as polymers or ceramics, it is recommended to use the same formula to compute both static and dynamic fracture toughness $[1,7]$. The criterion of the loading dynamic force oscillations fading in time must be fulfilled as the necessary condition for the abovementioned approach [13]. Thus, the criterion was fulfilled during dynamic examination.

In the study, static and dynamic fracture toughness ( $K_{I C}$ and $K_{I D}$, respectively) were calculated according to [13]:

$$
\begin{gathered}
K_{I C}=\frac{F_{S t M A X} R_{S t}}{b h^{3 / 2}} \psi(\tilde{\mathrm{u}})(1) \\
K_{I D}=\frac{F_{d y n M A X} R_{d y n}}{b h^{3 / 2}} \psi(\tilde{\mathrm{u}})(2)
\end{gathered}
$$

where: $F_{s t ~ M A X}$ is the maximal static force, $F_{d y n}$ ${ }_{M A X}$ is the maximal value of the dynamic force read from its time course; $R_{s t}$ is a span of supporting rollers in a three-point bending device, $R_{d y n}$ is a span of Charpy pendulum's buttresses; $b$ and $h$ are dimensions of a specimen's cross-section; $\psi(\tilde{\mathrm{u}})$ is the function of notch dimensions which has the following form $[1,3,7,10]$ :

$\psi(\tilde{\mathrm{u}})=\frac{1.5 \tilde{\mathrm{u}}^{1 / 2}\left[1.99-\tilde{\mathrm{u}}(1-\tilde{\mathrm{u}})\left(2.15-3.93 \tilde{\mathrm{u}}+2.7 \tilde{\mathrm{u}}^{2}\right)\right]}{(1+2 \tilde{\mathrm{u}})(1-\tilde{\mathrm{u}})^{3 / 2}}$

where: $\tilde{\mathrm{u}}=\mathrm{u} / \mathrm{h}$ is a normalized notch depth. All specimen's dimensions are presented in Figure 1.
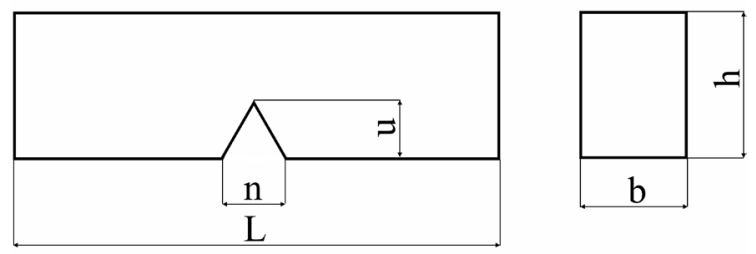

Fig. 1. Shape and dimensions of a specimen

\section{EXPERIMENTAL PROCEDURE}

Two kinds of strength test were performed on polymer notched beams: quasi-static, i.e. a three-point bending, as well as dynamic - an instrumented impact test. During the experiment, samples of two groups of materials were used: Epidian 5 epoxy resin cured with Z1 curing agent (E5+Z1(10\%)) and Epidian 53 epoxy resin cured with $Z 1$ curing agent $(\mathrm{E} 53+\mathrm{Z1}(10 \%))$. The amount of the curing agent in both cases was $10 \%$ of a total weight of epoxy resin. Each specimen had a shape of beam with a rectangular crosssection and a notch in the midspan, as shown in Figure 1. Such specimens were used for static and dynamic tests. Four sets of E5+Z1(10\%) samples and four sets of E53+Z1(10\%) samples were examined. The dimensions of specimens were as follows: $b \times h \times L=4 \times 10 \times 100 \mathrm{~mm}$.

The samples were fabricated in the laboratory of the Department of Production Engineering at room temperature $17-18^{\circ} \mathrm{C}$ and humidity $21-23 \%$. First of all, the epoxy resin and the curing agent were mixed together for 5 min using a mechanical paddle mixer with rpm=1130. Then, a chamber with a vacuum pump was used to deair the mixture. Two cycles of deairing were performed $(2 \times 5 \mathrm{~min})$. Subsequently, the assigned mold was filled with the mixture. Both E5+Z1(10\%) and E53+Z1(10\%) samples were fabricated using the same method. A few days later, the beam samples were taken out of the mold and milled to obtain $b$ $=4 \mathrm{~mm}$. The milling process was conducted using the vertical machining center FV580a. A shell mill made of high shear steel HSS with diameter $d=35 \mathrm{~mm}$ and a number of cutting edges $z=6$ was used. Milling rotation speed was $1150 \mathrm{rpm}$ while feed rate $V_{f}=52 \mathrm{~mm} / \mathrm{min}$. Afterwards, $\mathrm{V}$-notches were cut with an angle needle file and deepened with a cutter knife. By this technique, notches with the depth $u=2.7-2.9 \mathrm{~mm}$ and the bottom width $n=3.1-3.3 \mathrm{~mm}$ were fabricated.

All examinations took place at an ambient temperature. The three-point bending test was conducted with the universal testing machine (model Autograph AGS-X 5 kN, Shimadzu Corporation, Japan) equipped with an adequate loading device. First of all, a preliminary examination on two specimens was performed. The span $(R)$ of the supporting rollers was $80 \mathrm{~mm}$. It was observed that the crack propagation for $\mathrm{E} 53+\mathrm{Z} 1(10 \%)$ sample was growing much slower than the one for E5+Z1(10\%) sample. Thereby, a shorter span 
was adjusted for E53+Z1(10\%) specimens. Finally, for the main examination the span was $80 \mathrm{~mm}$ for $\mathrm{E} 5+\mathrm{Z} 1(10 \%)$ and $60 \mathrm{~mm}$ for $\mathrm{E} 53+\mathrm{Z1}(10 \%)$. The samples were loaded vertically very slowly (quasi-statically). Loading crosshead's velocity was $1 \mathrm{~mm} / \mathrm{min}$. Time, force and displacement were registered on a computer hard drive. The view of a loaded specimen during the three-point bending test is shown in Figure 2.

Dynamic tests were conducted with the instrumented Charpy pendulum (KB Prueftechnik GmbH, Hochdorf-Assenheim, Germany) equipped with a $7.5 \mathrm{~J}$ tup. A maximum velocity was $3.815 \mathrm{~m} / \mathrm{s}$ and a fall angle was $157.32^{\circ}$. The time course of the impact force at a frequency of $1 \mathrm{MHz}$ was registered by a built-in resistive sensor while the tup touched the specimen. The data such as force, energy, time and displacement were recorded on a hard drive by an appropriate A/D PC card (model NuDAQ PCI-9812, AdLink Technology Inc., Taipei, Taiwan).

\section{RESULTS AND DISCUSSION}

As a result of the three-point bending test $\mathrm{E} 5+\mathrm{Z} 1(10 \%)$ the specimens were broken in a brittle way whereas E53+Z1(10\%) specimens were not completely broken into two parts but a growing crack was observed. The microscopic views of a V-notch before and after the three-

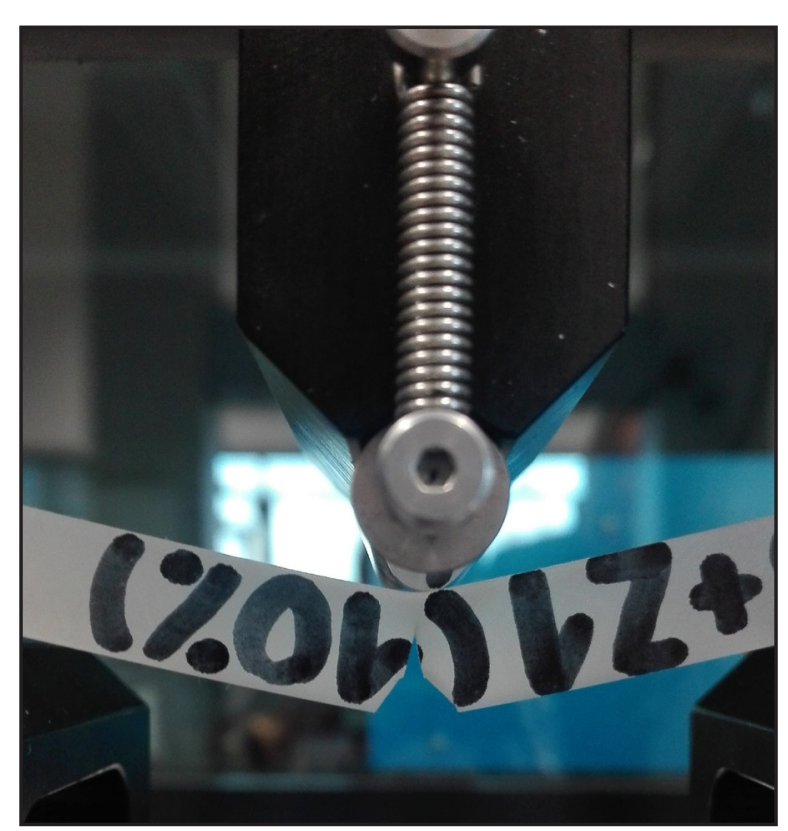

Fig. 2. The view of a loaded specimen during the three-point bending test point bending test are presented in Figures 3 and 4 for both kinds of specimens. In the case of E53+Z1(10\%) sample the dimensions of a crack growth are given. The values of the static force $F_{s t}$ versus displacement $s$ are plotted in Figures 5 and 6 for four E5+Z1(10\%) and E53+Z1(10\%) specimens. As can be noticed, the static force for $\mathrm{E} 53+\mathrm{Z1}(10 \%)$ samples was about four times higher than for E5+Z1(10\%). The value of the maximum static force $F_{s t M A X}$ for each specimen is given in Table 1. The average value of $F_{\text {st MAX }}$ for $\mathrm{E} 5+\mathrm{Z} 1(10 \%)$ specimens equals $19.7 \mathrm{~N}$ whereas for $\mathrm{E} 53+\mathrm{Z} 1(10 \%)$ it equals $78.4 \mathrm{~N}$. The maximum difference between $F_{\text {st MAX }}$ values for E5+Z1(10\%) and $\mathrm{E} 53+\mathrm{Z} 1(10 \%)$ samples is equal to $2.1 \mathrm{~N}$ and $12.1 \mathrm{~N}$, respectively.

As a result of the dynamic-Charpy test, the values of the dynamic force $F_{d y n}$ versus time $t$ were obtained and plotted in the next two graphs. Figures 7 and 8 show the values for four E5+Z1(10\%) and E53+Z1(10\%) specimens. As inferred, the dynamic force in both cases is at a similar level. The value of the maximum dynamic force $F_{d y n \text { MAX }}$ for each sample is given in Table 2 . The average value of $F_{d v n \text { MAX }}$ for E5+Z1(10\%) specimens equals $120.6 \mathrm{~N}$ whereas for $\mathrm{E} 53+\mathrm{Z1}(10 \%)$ it equals $134.4 \mathrm{~N}$. The maximum difference between $F_{d v n}$ ${ }_{M A X}$ values for $\mathrm{E} 5+\mathrm{Z} 1(10 \%)$ and $\mathrm{E} 53+\mathrm{Z} 1(10 \%)$ samples is equal to $26.7 \mathrm{~N}$ and $20.5 \mathrm{~N}$, respectively. The microscopic views of a fracture surface after the Charpy test are shown in Figures 9 and 10. Crack propagation and microcracks are clearly visible.

Figure 11 shows the average values of static and dynamic fracture toughness. As can be seen in the graph, for E5+Z1(10\%) specimens, the dynamic feature was over two times higher than the static one. Moreover, for E53+Z1 $(10 \%)$ static fracture toughness was approximately equal to dynamic fracture toughness.

\section{CONCLUSIONS}

The examination of static and dynamic fracture toughness were performed for $\mathrm{E} 5+\mathrm{Z} 1(10 \%)$ and $\mathrm{E} 53+\mathrm{Z} 1(10 \%)$ specimens. The maximum values of static and dynamic forces were obtained for two kinds of materials. The average maximum dynamic force was about six times higher than the average maximum static force for $\mathrm{E} 5+\mathrm{Z} 1(10 \%)$ and was about two times higher for $\mathrm{E} 53+\mathrm{Z1}(10 \%)$. It was noticed that E53+Z1(10\%) 


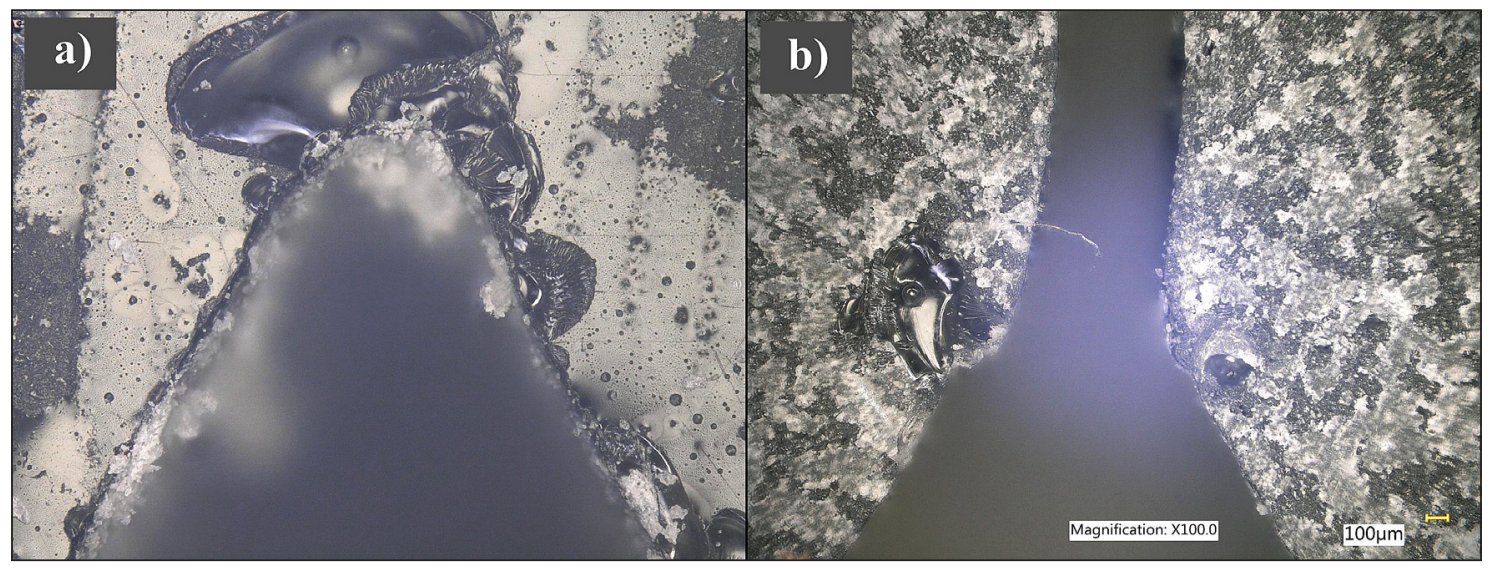

Fig. 3. The microscopic view of a V-notch for E5+Z1(10\%) specimen: a) before the three-point bending test, b) after the three-point bending test

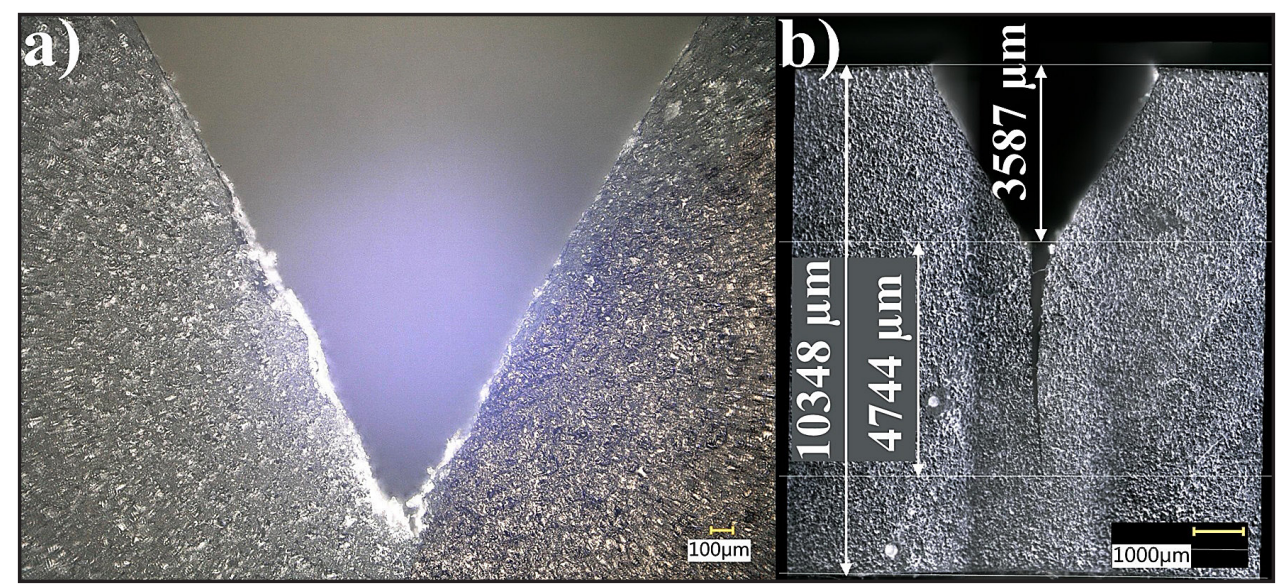

Fig. 4. The microscopic view of a V-notch for E53+Z1(10\%) specimen: a) before the three-point bending test, b) after the three-point bending test

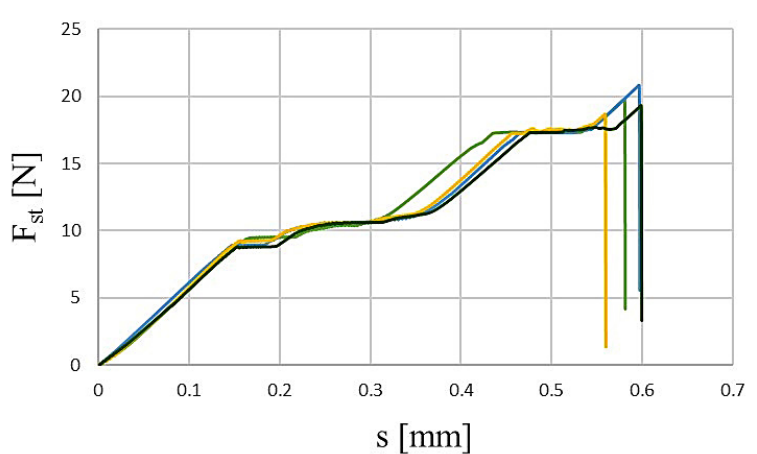

Fig. 5. Value of static force $F_{s t}$ versus displacement $s$ for four $\mathrm{E} 5+\mathrm{Z} 1(10 \%)$ specimens

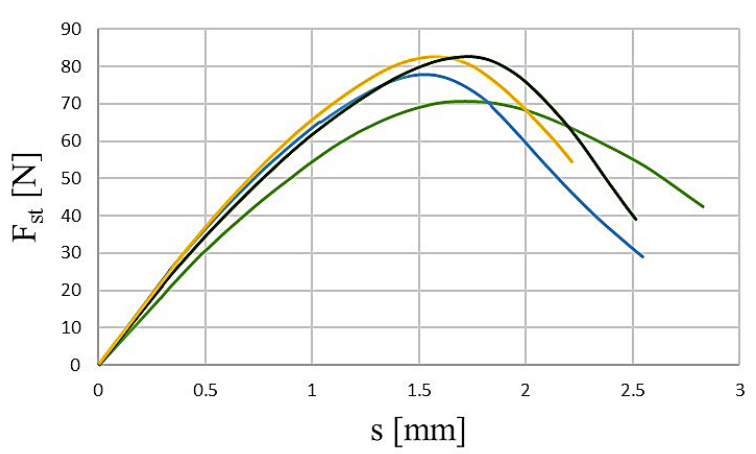

Fig. 6. Value of static force $F_{s t}$ versus displacement $s$ for four $\mathrm{E} 53+\mathrm{Z} 1(10 \%)$ specimens

Table 1. Value of the maximum static force for each specimen

\begin{tabular}{|l|c|c|c|c|c|c|c|c|}
\hline \multicolumn{1}{|c|}{ Type of specimen } & \multicolumn{4}{c|}{ E5+Z1(10\%) } & \multicolumn{4}{c|}{ E53+Z1(10\%) } \\
\hline \multicolumn{1}{|c|}{ Specimen no. } & 1 & 2 & 3 & 4 & 1 & 2 & 3 & 4 \\
\hline $\mathrm{F}_{\text {st MAX }}[\mathrm{N}]$ & 19.8 & 20.8 & 18.7 & 19.3 & 70.6 & 77.8 & 82.6 & 82.7 \\
\hline Average $\mathrm{F}_{\text {st MAX }}[\mathrm{N}]$ & \multicolumn{4}{|c|}{19.7} \\
\hline
\end{tabular}




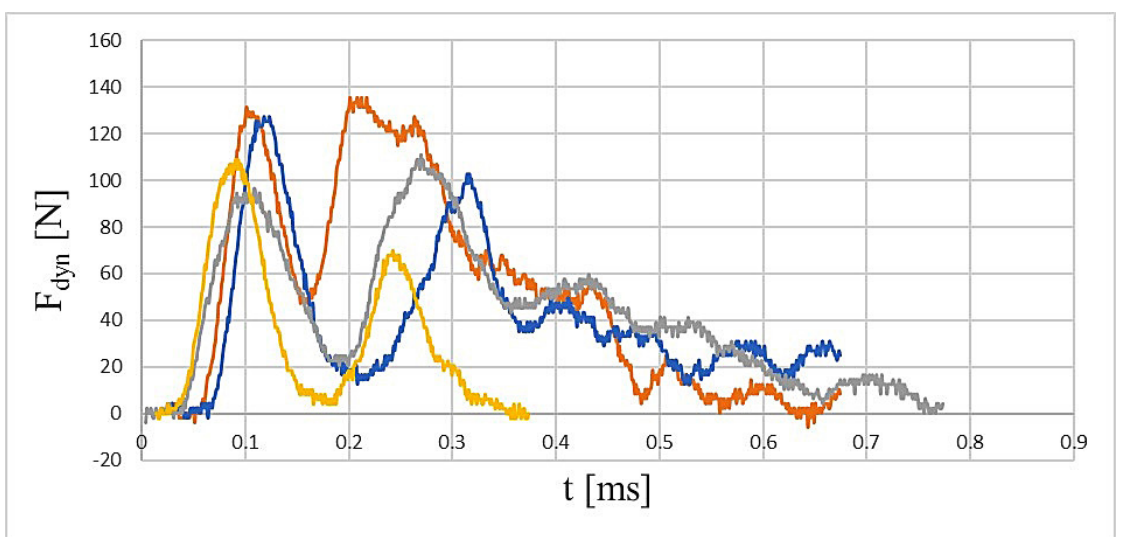

Fig. 7. Value of dynamic force $F_{d y n}$ versus time $t$ for E5+Z1(10\%) specimens

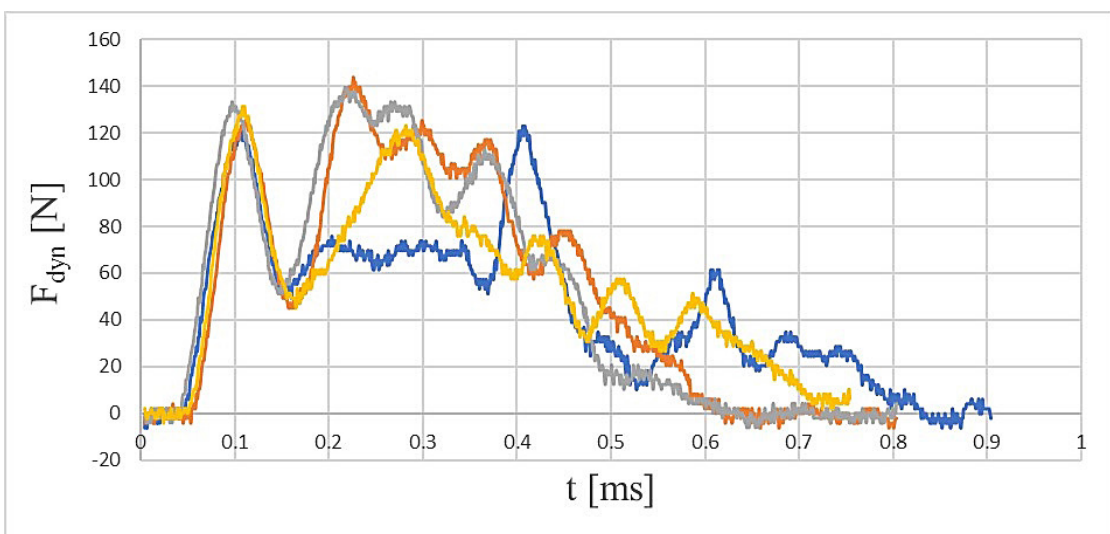

Fig. 8. Value of dynamic force $F_{d y n}$ versus time $t$ for E $53+Z 1(10 \%)$ specimens

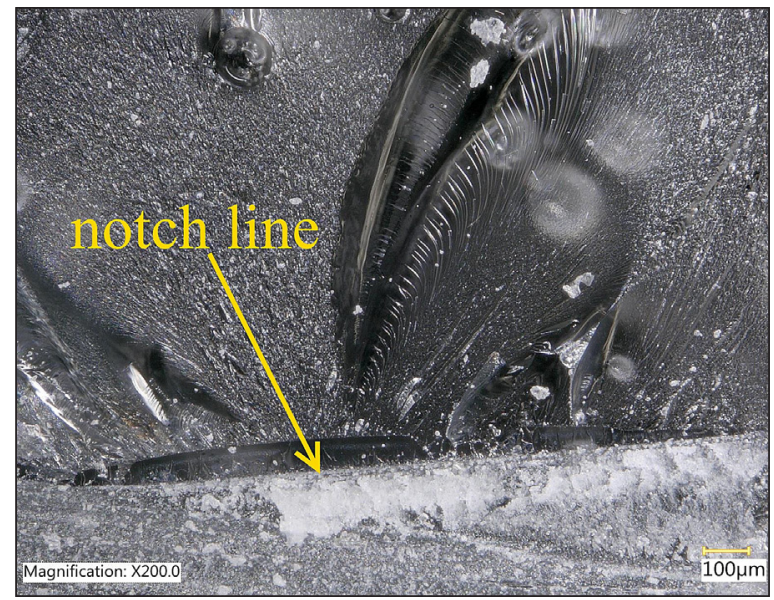

Fig. 9. The microscopic view of a crack propagation for E5+Z1(10\%) specimen after the Charpy test

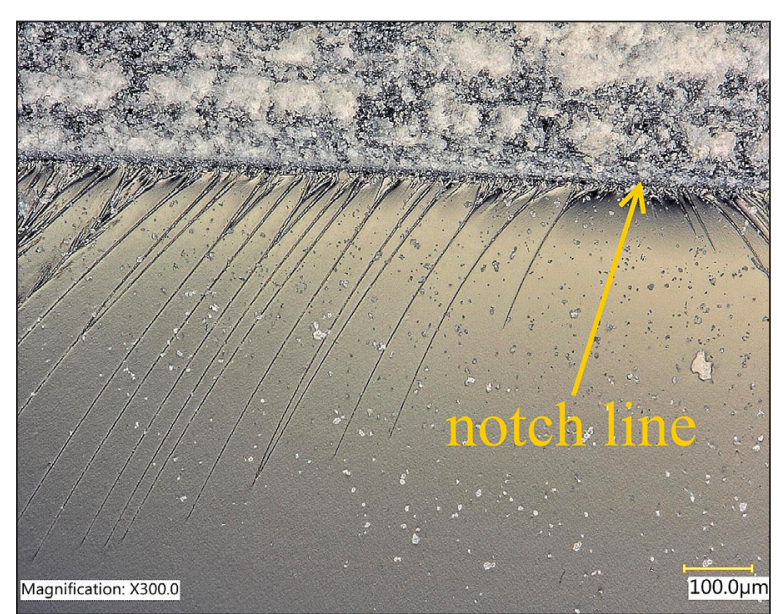

Fig. 10. The microscopic view of a crack propagation for $\mathrm{E} 53+\mathrm{Z} 1(10 \%)$ specimen after the Charpy test

Table 2. Value of the maximum dynamic force for each specimen

\begin{tabular}{|l|c|c|c|c|c|c|c|c|}
\hline \multicolumn{1}{|c|}{ Type of specimen } & \multicolumn{4}{|c|}{ E5+Z1(10\%) } & \multicolumn{4}{c|}{ E53+Z1(10\%) } \\
\hline \multicolumn{1}{|c|}{ Specimen no. } & 1 & 2 & 3 & 4 & 1 & 2 & 3 & 4 \\
\hline $\mathrm{F}_{\text {dyn MAX }}[\mathrm{N}]$ & 127.3 & 135.5 & 110.9 & 108.8 & 123.2 & 143.7 & 139.6 & 131.4 \\
\hline Average $\mathrm{F}_{\text {dyn MAX }}[\mathrm{N}]$ & \multicolumn{4}{|c|}{120.6} \\
\hline
\end{tabular}




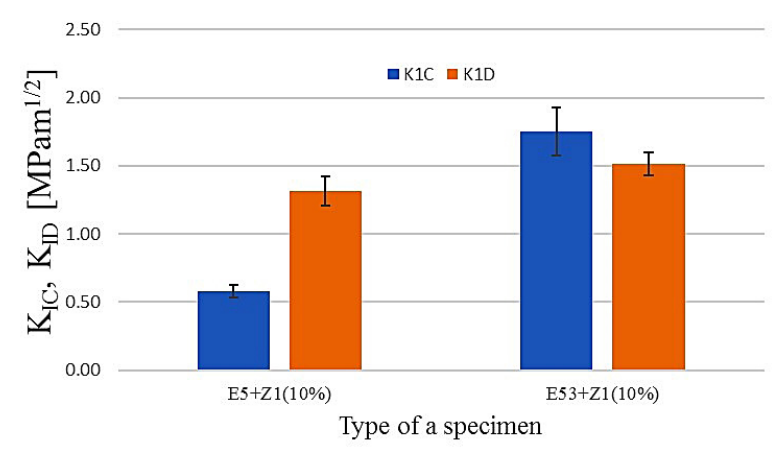

Fig. 11. Average value of $K_{I C}$ and $K_{I D}$ for two kinds of specimens

was more flexible than E5+Z1(10\%) which was quite brittle. $K_{I D}$ was much higher than $K_{I C}$ for $\mathrm{E} 5+\mathrm{Z1}(10 \%)$ samples whereas for E53+Z1(10\%) specimens it was a bit lower. As can be inferred, the more flexible the resin is, the less visible the differences between $K_{I C}$ and $K_{I D}$ are. In the case of $\mathrm{E} 53+\mathrm{Z} 1(10 \%)$ the fracture resistance was at a similar level for both static and dynamic test. For E5+Z1(10\%) a stress wave was probably growing gradually during the static loading but it had no time to propagate during the dynamic loading.

As described above, a value of dynamic fracture toughness could be different from its static counterpart. Thus, it would be interesting to examine the values for other materials. Furthermore, it also appears to be worth analyzing the influence of changing conditions on the fracture toughness of materials, e.g. the influence of thermal shock on the value of static and dynamic fracture toughness of polymers. Moreover, it would be interesting to deeply analyze the microscopic views of V-notches after the tests and discuss the directions of crack propagation. It was observed that microcracks had appeared in the fracture surface of the tested specimens.

\section{REFERENCES}

1. Fengchun J., Ruitang L., Xiaoxin Z., Vecchio K. and Rohatgi A. Evaluation of dynamic fracture toughness KId by Hopkinson pressure bar loaded instrumented Charpy impact test. Engineering Fracture Mechanics, 71(3), 2004, 279-287.

2. Inoue T., Kimura Y. and Ochiai S. Static fracture toughness of fail-safe steel. Scripta Materialia, 65(6), 2011, 552-555.

3. ISO 179-2. Plastics - Determination of Charpy Impact Properties - Part 2: Instrumented Impact Test, 1997.
4. Jin F., Li X. and Park S. Synthesis and application of epoxy resins: A review. Journal of Industrial and Engineering Chemistry, 29, 2015, 1-11.

5. Kłonica M. Comparative analysis of effect of thermal shock on adhesive joint strength. Advances in Science and Technology Research Journal, 10(32), 2016, 263-268.

6. Kłonica M. Impact of Thermal Fatigue on Young's Modulus of Epoxy Adhesives. Advances in Science and Technology Research Journal, 9(28), 2015, 103-106.

7. Marsavina L. and Sadowski T. Dynamic fracture toughness of polyurethane foam. Polymer Testing, 27(8), 2008, 941-944.

8. Pakdaman A. M., Moosavi M. and Mohammadi S. Experimental and numerical investigation into the methods of determination of mode I static fracture toughness of rocks. Theoretical and Applied Fracture Mechanics, 100, 2019, 154-170.

9. Perez-Martin M. J., Erice B. and Galvez F. Experimental determination of the dynamic fracture-initiation toughness of high-strength metals. Engineering Fracture Mechanics, 205, 2019, 498-510.

10. Sadowski T., Boniecki M., Librant Z. and Ruiz C. Fracture Process of Monolythic Polycrystalline Ceramics (Al2O3 and $\mathrm{MgO}$ ) Under Quasi-Static and Dynamic Loading. Proceedings of Brittle Matrix Composites 5, Edited by A.M. Brandt, V. C. Li, and I. H. Marshall. Woodhead Publishing Ltd., 1997.

11. Samborski S. Prediction of delamination front's advancement direction in the CFRP laminates with mechanical couplings subjected to different fracture toughness tests. Composite Structures, 202, 2018, 643-650.

12. Samborski S., Rzeczkowski J. and Paśnik J. Issues of Direct Application of Fracture Toughness Determination Procedures to Coupled Composite Laminates. IOP Conference Series: Materials Science and Engineering, 416, 2018, 1-5.

13. Samborski S. and Sadowski T. Dynamic Fracture Toughness of Porous Ceramics. Journal of the American Ceramic Society, 93(11), 2010, 3607-3609.

14. Shen Y., Li G. and An Q. Enhanced fracture toughness of boron carbide from microalloying and nanotwinning. Scripta Materialia, 162, 2019, 306-310.

15. Shi X., Yao W., Liu D., Xia K., Tang T. and Shi Y. Experimental study of the dynamic fracture toughness of anisotropic black shale using notched semicircular bend specimens. Engineering Fracture Mechanics, 205, 2019, 136-151.

16. Wang R.M., Zheng S.R. and Zheng Y.G. Polymer Matrix Composites and Technology. Elsevier, 2011.

17. Wu T., Liu Y., Li N. Huang G., Qu C. and Xiao $\mathrm{H}$. Cryogenic mechanical properties of epoxy resin toughened by hydroxyl-terminated polyurethane. Polymer Testing, 74, 2019, 45-56. 